\title{
Potencial fitorremediador das microalgas no tratamento combinado de lixiviado de aterro sanitário e água residual doméstica*
}

\section{Phytoremediation potential of microalgae in the combined treatment of landfill leachate and domestic wastewater}

Data de entrada: $08 / 06 / 2020$

Data de aprovação: $21 / 10 / 2020$
ORCID ID

Marinho BTS (DD https://orcid.org/0000-0001-7452-151X
Martins IGM (D) https://orcid.org/0000-0002-8726-1478

\section{Resumo}

O lixiviado de aterro sanitário possui uma elevada concentração de compostos orgânicos recalcitrantes, de nitrogênio amoniacal, de salinidade e uma baixa concentração de fósforo, um fator limitante para o crescimento de microalgas. A fim de aumentar a eficiência de remoção de nutrientes, a pesquisa realizou uma combinação do lixiviado com o esgoto doméstico por meio de 3 operações em bateladas, num período de 20 dias cada. Foram definidas três misturas de esgoto e lixiviado, de 50\% / 50\% (M1), 70\% / 30\% (M2) e 90\% / 10\% (M3), respectivamente. E, como inóculo, um cultivo de microalgas de um efluente de bovinocultura. Foram realizadas análises de nitrogênio amoniacal, fósforo solúvel, SSV, clorofila a e pH. Foi avaliado que M3 apresentou uma remoção de nitrogênio amoniacal e fósforo solúvel em um intervalo menor do que as demais, e ainda um maior crescimento de clorofila $a$, isso devido a sua menor limitação de fósforo, decorrente da alta concentração de esgoto e à ausência de inibidores.

Palavras-chave: Biorremediação. Esgoto doméstico. Fator limitante. Fitorremediação. Limitação de fósforo. Lixiviado de aterro. Microalga.

\section{Abstract}

Landfill leachate has a high concentration of recalcitrant organic compounds, ammonia nitrogen, salinity and a low concentration of phosphorus, a limiting factor for the growth of microalgae. In order to increase the efficiency of nutrient removal, the research carried out a combination of leachate with domestic sewage through 3 batch operations, in a period of 20 days each. Three mixtures of sewage and leachate were defined, 50\%/50\% (M1), 70\% / 30\% (M2) and 90\% / $10 \%$ (M3), respectively. And as an inoculum a microalgae cultivation of a bovine culture effluent. Analysis of ammoniacal nitrogen, soluble phosphorus, VSS, chlorophyll a and $\mathrm{pH}$ were performed. It was evaluated that M3 showed a removal of ammoniacal nitrogen and soluble phosphorus in a shorter interval than the others and even greater growth of chlorophyll a, due to its lower phosphorus limitation, due to the high concentration of sewage and the absence of inhibitors.

Keywords: Bioremediation. Domestic sewage. Limiting factor. Phytoremediation. Phosphorus limitation. Leachate from landfill. Microalgae.

\footnotetext{
* Este artigo é dedicado à memória de Fábio Valente Alves, amigo e colaborador.
}

\footnotetext{
${ }^{1}$ Universidade Federal de Itajubá - Itabira - Minas Gerais - Brasil.

$*$ Autora correspondente: brenda.scardiniahotmail.com.
} 


\section{INTRODUÇÃO}

As atividades desenvolvidas pela humanidade e o seu modo de vida, decorrentes do rápido crescimento populacional, têm agravado o aumento da geração de efluentes. Os resíduos sólidos urbanos são enviados para a sua disposição final em aterros sanitários dos municípios. Todavia, nesses locais ocorre a produção do lixiviado, popularmente conhecido por chorume, que se refere ao líquido oriundo dos processos de decomposição microbiológica, química e física dos resíduos sólidos urbanos presentes nos aterros.

A composição química e microbiológica do lixiviado é complexa, pois as mesmas são totalmente relacionadas às características dos resíduos que são dispostos nos aterros, além do tipo de operação e da condição ambiental local. Normalmente o chorume possui altas concentrações de compostos orgânicos recalcitrantes, de nitrogênio amoniacal e salinidade, além de baixa presença de fósforo, o que dificulta seu tratamento (PASKULIAKOVA; TONRY; TOUZET, 2016).

Devido a sua composição, o lixiviado possui um elevado potencial poluidor. Tal fato evidencia a necessidade de seu tratamento, devido aos diversos problemas ambientais que o mesmo pode acarretar, como contaminação do solo, das águas superficiais e subterrâneas, além de poder se transformar em um vetor de doenças na saúde pública.

Assim como os resíduos sólidos, a geração do esgoto é uma das consequências do desenvolvimento populacional. Segundo Acién, Amaral e Serrano (2016), as águas residuais possuem em sua composição uma grande similaridade aos meios onde são cultivadas as microalgas, tendo em abundância nitrogênio, carbono, fósforo e outros compostos secundários, estas essenciais para o desenvolvimento das microalgas. $O$ que torna uma possibilidade o uso desse efluente como um meio para a produção de biomassa algal além da remediação do mesmo.
A fitorremediação à base de microalgas tem se tornado uma alternativa no tratamento de efluentes domésticos em todo o mundo (ACEVEDO, PINO, PEÑUELA, 2017; GANI et al., 2015; ÓRPEZ et al., 2009; RAWAT et al., 2010; SAHU, 2014), pois o mesmo pode oferecer um tratamento a partir da absorção de nutrientes como compostos nitrogenados do lixiviado de aterro sanitários, além da presença em grande quantidade de nutrientes enriquecidos, presentes na água residual doméstica. A assimilação desses nutrientes é distinta e varia quanto às características das espécies das microalgas em desenvolvimento, além da sua forma de adaptação e competição, e às condições em que o meio se encontra.

Devido às características das microalgas e ao uso que fazem de nutrientes em excesso no efluente, principalmente nitrogênio e fósforo, elas são vistas como uma alternativa nos avanços de tratamentos de efluentes. Em razão das altas relações de nitrogênio e fósforo presentes em alguns efluentes, como é o caso do lixiviado de aterro sanitário, a adição de fosfato pode garantir os nutrientes necessários para o cultivo das microalgas.

Diante do exposto, o presente estudo avaliou a produção de biomassa algal a partir do tratamento combinado de lixiviado de aterro sanitário e esgoto doméstico. $O$ tratamento em conjunto tem por objetivo sanar a limitação de fósforo existente no lixiviado para o crescimento das microalgas. Além disso, essa combinação pode representar uma eficiente alternativa para tratamento e recuperação dos nutrientes do lixiviado em diversas localidades.

\section{OBJETIVOS}

Esse trabalho tem como objetivo avaliar a eficiência das microalgas na remoção dos nutrientes em diferentes proporções de lixiviado de aterro sanitário e esgoto doméstico, quando combinados. 


\section{METODOLOGIA}

O estudo foi realizado na cidade de Itabira, do estado de Minas Gerais, no Brasil. O experimento e os ensaios laboratoriais foram realizados no laboratório de microbiologia e de saneamento ambiental, do Instituto de Ciências Puras e Aplicadas (ICPA) no campus avançado da Universidade Federal de Itajubá, em Itabira, Minas Gerais.

Foram definidos 3 tratamentos distintos com diferentes proporções de lixiviado de aterro sanitário e esgoto doméstico secundário. O lixiviado foi coletado no aterro sanitário de Itabira. Já o esgoto doméstico, na saída do reator anaeróbio de fluxo ascendente (UASB) da Estação de Tratamento de Esgoto (ETE) Laboreaux, operada pelo Serviço Autônomo de Água e Esgoto (SAAE), também em Itabira.

Para cada tratamento foram utilizados 5 erlenmeyers, sendo cada um deles preenchidos com $200 \mathrm{~mL}$ da mistura de efluente. Em que foi uti- lizado um inóculo de cultivo de microalgas em efluente de bovinocultura (10\% v.v-1) disponibilizado pela Universidade Federal de Viçosa, em Viçosa, Minas Gerais.

As altas concentrações de nitrogênio amoniacal presentes no lixiviado de aterro expressam uma dificuldade em seu tratamento. Segundo Paskuliakova, Tonry e Touzet (2016), as concentrações podem apresentar variação de 30 a $3000 \mathrm{mg} \mathrm{L-1}$. Soma-se $\mathrm{a}$ isso o fato de o nitrogênio amoniacal livre conferir toxicidade ao meio, interferindo negativamente na remediação a partir das microalgas, em comparação com demais efluentes (PASKULIAKOVA; TONRY; TOUZET, 2016). Tendo isso como base, o esgoto utilizado na pesquisa foi diluído 5 vezes antes da inoculação, a fim de atingir concentrações mais baixas de nitrogênio amoniacal e minimizar as chances de inibição do crescimento das microalgas. As relações utilizadas estão expressas na Tabela 1.

Tabela 1 - Concentrações utilizadas nas misturas.

\begin{tabular}{|c|c|c|c|}
\hline $\begin{array}{c}\text { Relação } \\
\text { Esgoto/Lixiviado }\end{array}$ & $\begin{array}{c}\text { Esgoto doméstico } \\
\text { (saida do reator) }\end{array}$ & $\begin{array}{c}\text { Lixiviado de aterro } \\
\text { (diluído) }\end{array}$ & Inóculo \\
\hline $50 \% / 50 \%$ & $90 \mathrm{~mL}$ & $90 \mathrm{~mL}$ & $20 \mathrm{~mL}$ \\
\hline $70 \% / 30 \%$ & $126 \mathrm{~mL}$ & $54 \mathrm{~mL}$ & $20 \mathrm{~mL}$ \\
\hline $90 \% / 10 \%$ & $162 \mathrm{~mL}$ & $18 \mathrm{~mL}$ & $20 \mathrm{~mL}$ \\
\hline
\end{tabular}

As misturas foram colocadas em uma mesa agitadora sob agitação constante de $100 \mathrm{rpm}$ durante todo o período de operação, de modo a garantir a iluminação uniforme de todas as células em suspensão, pela luminosidade natural presente no local, como apresentada na Fig. 1. Cada mistura foi identificada segundo a sua relação, sendo elas: M1 (50\% / 50\%), M2 (70\% / 30\%) e M3 (90\% / 10\%).

O estudo foi realizado durante os meses de março a junho de 2019, com a realização de 3 bateladas. Cada operação teve a duração de 20 dias.
As coletas para monitoramento foram realizadas nos dias 0 (dia do preparo das amostras), 6, 9, 13, 16 e 20.

Durante os 20 dias, as amostras de cada tratamento foram coletadas, como mostra a Fig. 2, para a realização das análises, onde para cada uma foi monitorada as variáveis de $\mathrm{pH}$, Clorofila a (Chlo a), Sólidos Suspensos Voláteis (SSV) e Sólidos Suspensos Totais (SST), assim como Nitrogênio Amoniacal (N-NH4 +) e Fósforo Solúvel (P). Para a leitura do $\mathrm{pH}$ foi utilizada a sonda multiparâmetro Hach, modelo HQQ40d. A determinação da Chlo a 
foi realizada a partir da técnica de extração com etanol $80 \%$, como descrito na norma holandesa (Nederlands Norm, 1981), com base em Nush
(1980). Os demais parâmetros foram analisados segundo Standard Methods for the Examination of Water and Wastewater (APHA, 2012).

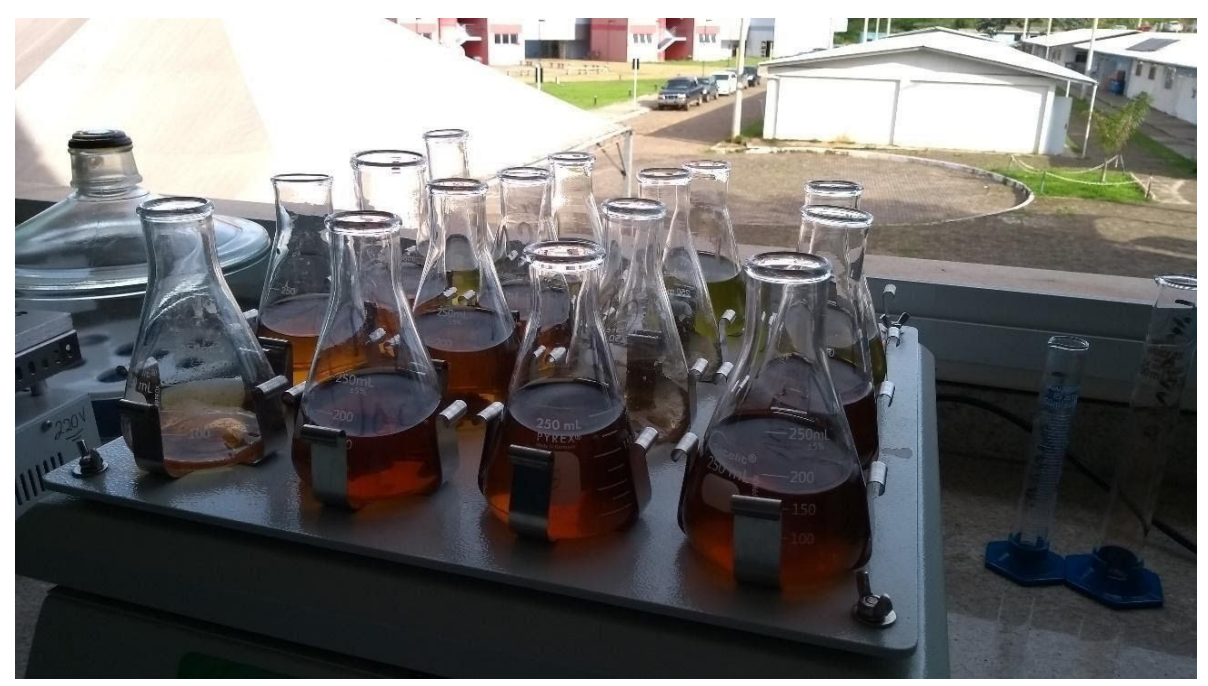

Figura 1 - Erlenmeyers dispostos na mesa agitadora

A análise dos dados foi executada a partir da plotação de gráficos para as diferentes bateladas, com os resultados das misturas de M1, M2 e M3. Com isso, foi possível analisar, individualmente e em conjunto, a taxa de crescimento das microalgas e a assimilação de nutrientes ( $\mathrm{N}$ e $\mathrm{P}$ ) pelas mesmas, além de serem levantados os fatores que dificultaram o crescimento das microalgas no meio.

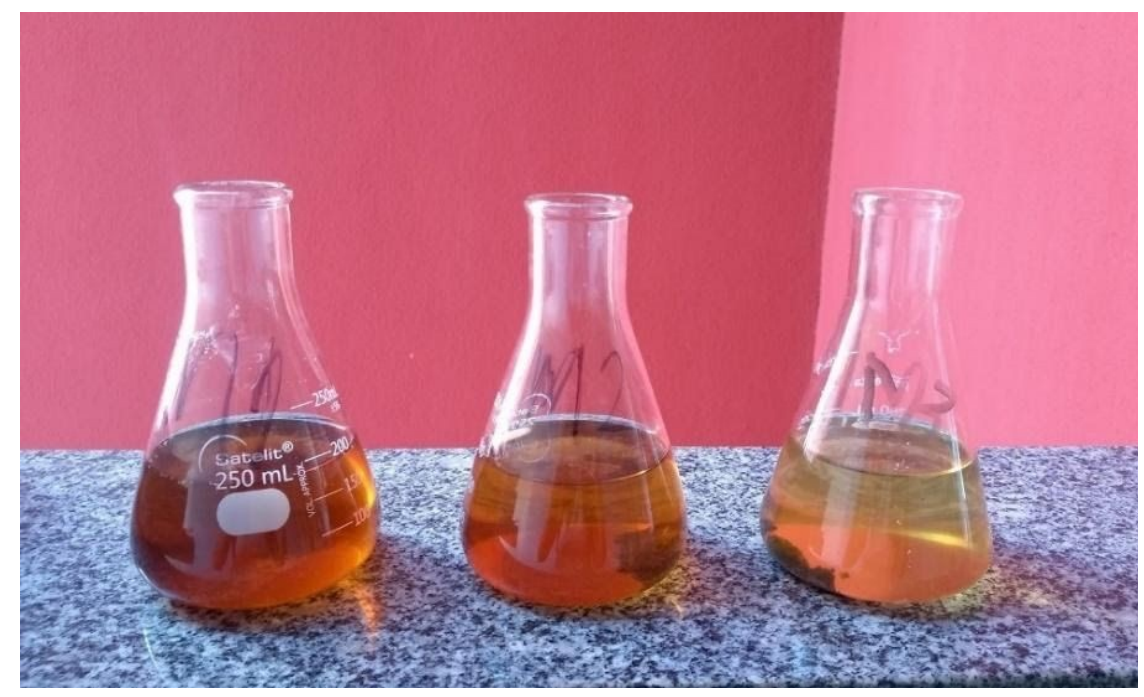

Figura 2 - Erlenmeyers com as Misturas na primeira coleta 


\section{RESULTADOS E DISCUSSÃO}

\subsection{Lixiviado de Aterro Sanitário e Água Residual Doméstica}

No que se refere ao lixiviado de aterro utilizado para a realização do experimento, o mesmo apresentou as características expressas na Tabela 2. Pela caracterização, foi possível observar que o lixiviado apresentou os aspectos expressos por Paskuliakova, Tonry e Touzet (2016), possuindo altas concentrações de compostos orgânicos recalcitrantes, de nitrogênio amoniacal e salinidade, além de baixa presença de fósforo em sua concentração.

Zhao et al. (2014) trabalharam com lixiviado com características semelhantes ao do presente estudo. Em sua caracterização, o lixiviado apresentou uma condutividade de $14.390\left(\mu \mathrm{S} \mathrm{cm}^{-1}\right)$, nitrogênio total de $1.786\left(\mathrm{mg} \mathrm{L}^{-1}\right)$, nitrogênio amoniacal de $1.381\left(\mathrm{mg} \mathrm{L}^{-1}\right)$ e fósforo total de 4,0 $\left(\mathrm{mg} \mathrm{L}^{-1}\right)$. Ou seja, uma relação N/P de 446,5/1, enquanto o lixiviado utilizado neste estudo apresentou uma relação N/P de 302,5/1. Ambos destacaram o fósforo como um nutriente limitante para o crescimento das microalgas.

Tabela 2 - Características do lixiviado de aterro sanitário bruto.

\begin{tabular}{|c|c|}
$\mid 2$ & Variáveis \\
\hline $\mathrm{pH}$ & 8,14 \\
\hline Condutividade $\left(\mu \mathrm{S} \mathrm{cm}^{-1}\right)$ & 14.270 \\
\hline Clorofila $a\left(\mathrm{mg} \mathrm{L}^{-1}\right)$ & 0 \\
\hline $\mathrm{SSV}\left(\mathrm{mg} \mathrm{L}^{-1}\right)$ & 35 \\
\hline $\mathrm{SST}\left(\mathrm{mg} \mathrm{L}^{-1}\right)$ & 76 \\
\hline Nitrogênio Total $\left(\mathrm{mg} \mathrm{L}^{-1}\right)$ & 1.059 \\
\hline Nitrogênio Amoniacal $\left(\mathrm{mg} \mathrm{L}^{-1}\right)$ & 548,50 \\
\hline Fósforo Total $\left(\mathrm{mg} \mathrm{L}^{-1}\right)$ & 3,50 \\
\hline
\end{tabular}

O inóculo utilizado foi obtido na Universidade Federal de Viçosa, em Viçosa, Minas Gerais, originado do cultivo de microalgas a partir do tratamento de efluente da bovinocultura em lagoas de alta taxa. 0 mesmo foi caracterizado conforme apresenta a Tabela 3.

Tabela 3 - Características do inóculo.

\begin{tabular}{|c|c|}
\hline \multicolumn{2}{|c|}{ Variáveis } \\
\hline $\mathrm{pH}$ & 6,09 \\
\hline Condutividade $\left(\mu \mathrm{S} \mathrm{cm}^{-1}\right)$ & 1,23 \\
\hline Clorofila $a\left(\mathrm{mg} \mathrm{L}^{-1}\right)$ & 280 \\
\hline $\mathrm{SSV}\left(\mathrm{mg} \mathrm{L}^{-1}\right)$ & 310 \\
\hline $\mathrm{SST}\left(\mathrm{mg} \mathrm{L}^{-1}\right)$ & 18,13 \\
\hline Nitrogênio Total $\left(\mathrm{mg} \mathrm{L}^{-1}\right)$ & 4,65 \\
\hline Nitrogênio Amoniacal $\left(\mathrm{mg} \mathrm{L}^{-1}\right)$ & 1,99 \\
\hline Fósforo Total $\left(\mathrm{mg} \mathrm{L}^{-1}\right)$ & 3,50 \\
\hline
\end{tabular}

\subsection{Análise do Crescimento Microalgal}

Para avaliar o crescimento microalgal foram realizadas inicialmente análises de SSV, que representa a concentração de biomassa total, e a clorofila $a$, sendo esta utilizada como indicadora do desenvolvimento das microalgas, como apresenta a Fig. 3.

Comparando o comportamento dos resultados obtidos de sólidos suspensos voláteis e de clorofila a se observa que o aumento da biomassa implicou no aumento da clorofila. Isso sugere que a biomassa produzida é predominantemente composta por microalgas.

Sabe-se ainda que o esgoto apresenta características distintas do lixiviado de aterro, com menores concentrações de substâncias que possam inibir o crescimento de microalgas, e por isso há uma tendência de apresentar uma melhor assimilação de nutrientes. Sendo assim, analisando a Fig. 3 é possível observar que houve o crescimento inicialmente no $\mathrm{M} 3$, isso provavelmente devido à maior proporção de esgoto doméstico e à menor presença de inibidores que poderiam afetar o processo de crescimento microalgal presentes no lixiviado. 
Batelada 1

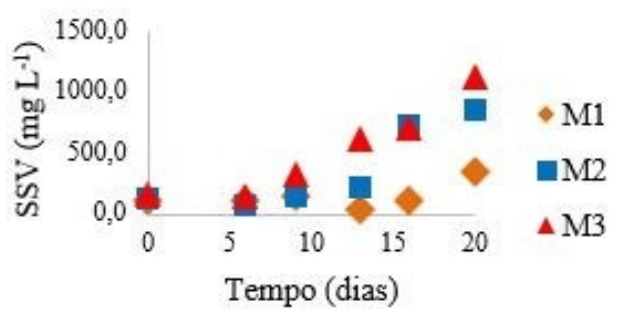

Batelada 2

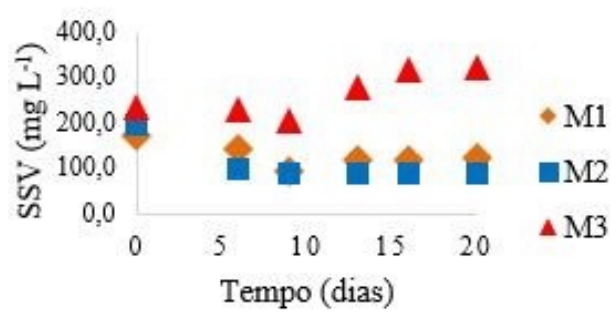

Batelada 3

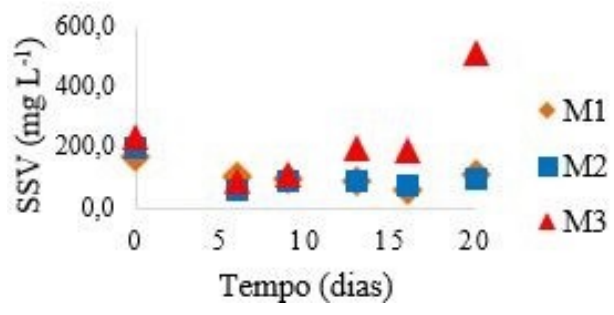

Batelada 1

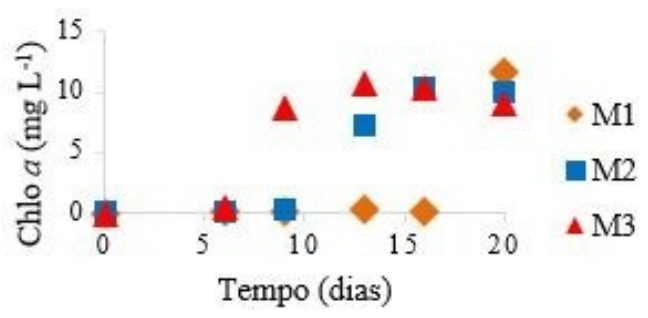

Batelada 2

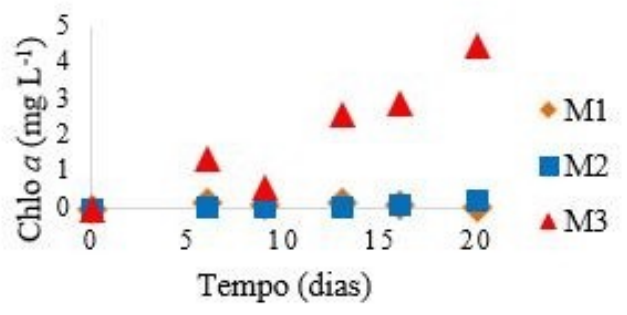

Batelada 3

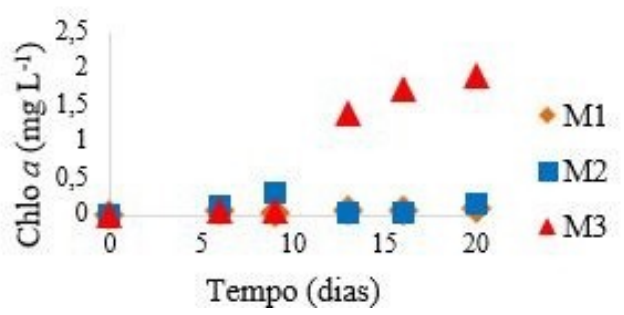

Figura 3 - Curvas de SSV e Chlo $a$.

García-Gozalbes, Arbib e Perales-Vargas-Machuca (2014) apresentam em sua pesquisa com crescimento de microalgas em esgoto doméstico uma média de $39 \mathrm{mg} \mathrm{L}^{-1}$ de SSV antes da remediação e valores próximos de $1.400 \mathrm{mg} \mathrm{L}^{-1}$ ao final de sua pesquisa, para um efluente da saída do reator UASB. Essa taxa de crescimento pode ser devida às condições operacionais existentes, em que houve o controle da luminosidade e um tempo de crescimento mais elevado, visto que o estudo foi realizado em um total de 25 dias. Comparada com o estudo em questão, a primeira batelada foi a que obteve maiores valores de SSV, ultrapassando os $1.100 \mathrm{mg} \mathrm{L}^{-1}$, em M3. Por mais que os valores fossem distintos, o crescimento apresentou um comportamento semelhante aos resultados de García-Gozalbes, Arbib e Perales-Vargas-Machuca.

Zhao et al. (2014) utilizaram em seu estudo uma cultura mista de esgoto doméstico com diferentes proporções $(0 \%, 5 \%, 10 \%, 15 \%$ e $20 \%)$ de lixiviado de aterro sanitário. No $12^{\circ} \mathrm{dia}$, a concentração máxima de clorofila $a$ foi alcançada justamente com a mistura que apresentava $10 \%$ de lixiviado, um valor de $22 \mathrm{mg} \mathrm{L}^{-1}$.

Comparando novamente com o estudo em questão, no $13^{\circ}$ dia da batelada 1 foi obtido o valor máximo de clorofila a de $10,78 \mathrm{mg} \mathrm{L}^{-1}$, na mistura que teve o maior crescimento microalgal (M3). 
Percebe-se ainda na Fig. 3 que a clorofila na terceira batelada foi menor do que nas demais, atingindo um valor máximo de $1,93 \mathrm{mg} \mathrm{L}^{-1}$, enquanto na primeira batelada foi de $10,78 \mathrm{mg} \mathrm{L}^{-1}$, ambos em M3. Um fator que pode ter interferido nessa variação é a temperatura do ambiente, como mostrado na Tabela 4.

Tabela 4 - Temperaturas mínimas, médias e máximas durante as operações.

\begin{tabular}{|c|c|c|c|}
\hline Temperatura & Batelada 1 & Batelada 2 & Batelada 3 \\
\hline Mínima (C) & 12,3 & 13,1 \\
\hline Média (C) & 22,3 & 20,8 \\
\hline Máxima (C) & 28,9 & 27,3 \\
\hline
\end{tabular}

Condições ambientais que não são controladas, como a temperatura, podem modificar taxas de crescimento e, portanto, impactam a eficiência de uma unidade de produção. Meio de crescimento em pistas rasas ou tubos estreitos, geralmente usados para produção de alta taxa, são susceptíveis a experimentar grandes e rápidas flutuações de temperatura, dependendo da região geográfica da localidade e das variações sazonais (RAS, STEYER e BERNARD, 2013). Sendo assim, uma explicação para o crescimento mais acelerado na batelada 1 é devido à temperatura mais elevada quando comparada com as demais bateladas em que a sucedem.

\subsection{Análise da remoção de nutrientes}

Com o intuito de avaliar a remoção de nutrientes pelas diferentes misturas, foram realizadas análises de $\mathrm{N}-\mathrm{NH}_{4}^{+}$e fósforo solúvel, com gráficos da remoção de nutrientes em cada batelada.

Comparando o comportamento da remoção de nutrientes das misturas, observa-se que M3 no dia 13 apresentava uma baixa concentração média de fósforo solúvel e praticamente uma inexistência de nitrogênio amoniacal em todas as bateladas. Comparando esse resultado com as outras misturas, M2 apresentava no dia uma concentração média de nitrogênio amoniacal de todas bateladas iguais a $58,3 \mathrm{mg} \mathrm{L}^{-1} \mathrm{e}$
1,27 $\mathrm{mgL}^{-1}$ defósforosolúveleM1 de 110,74 $\mathrm{mgL}^{-1} \mathrm{e}$ $1,9 \mathrm{mg} \mathrm{L}^{-1}$, respectivamente.

Zhao et al. (2014) realizaram um experimento similar, com esgoto doméstico combinado com o lixiviado de aterro em proporções distintas em um intervalo de tempo de 12 dias, na proporção $10 \%$ de lixiviado, igual ao M3 da pesquisa, e obtiveram no $12^{\circ}$ dia uma eficiência de remoção de nitrogênio amoniacal de $99 \%$, valor próximo ao obtido no dia 13 da M3, sendo de aproximadamente $90,15 \%$. No entanto, vale ressaltar que as outras misturas (M1 e M2) continuaram a remover nutrientes, chegando às concentrações médias de todas as bateladas de $17,73 \mathrm{mg} \mathrm{L}^{-1} \mathrm{e}$ $3,1 \mathrm{mg} \mathrm{L}^{-1}$ de e N-NH${ }_{4}^{+} 1,21$ e $0,72 \mathrm{mg} \mathrm{L}^{-1} \mathrm{~d}$ e fósforo solúvel, respectivamente, no $20^{\circ}$ dia.

Constata-se que as misturas que apresentam maior concentração de lixiviado de aterro em sua composição (M1 e M2) consequentemente possuem uma maior presença de nitrogênio amoniacal e um maior desequilíbrio da relação N/P, ocasionando maior dificuldade no desenvolvimento das microalgas nas respectivas misturas.

Com o intuito de entender como os mecanismos de remoção dos nutrientes pelas microalgas nas 3 misturas se dão, foram realizadas análises de pH durante as bateladas. Na Tabela 5 são apresentados os valores do $\mathrm{pH}$ da $3^{\mathrm{a}}$ batelada. 
Batelada 1

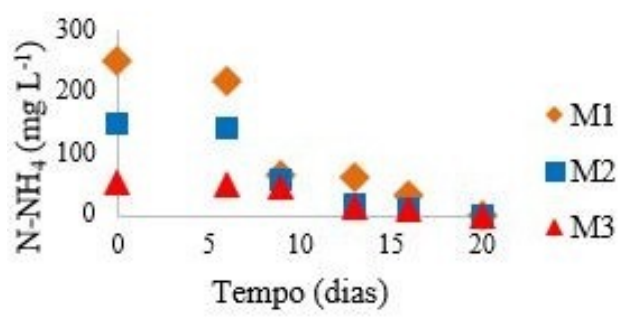

Batelada 2

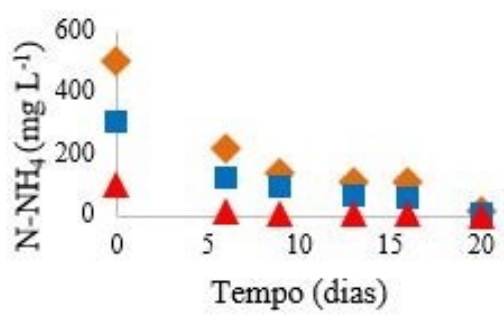

Batelada 3

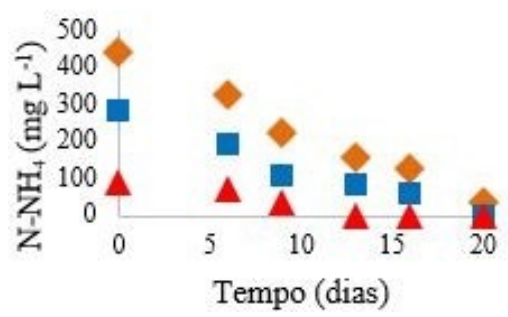

Batelada 1

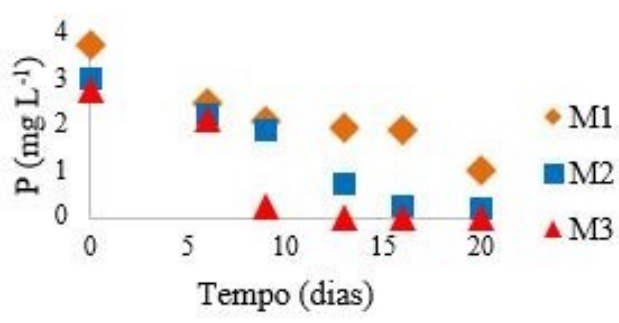

Batelada 2

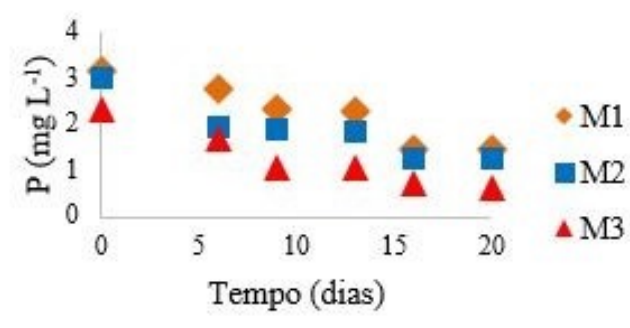

Batelada 3

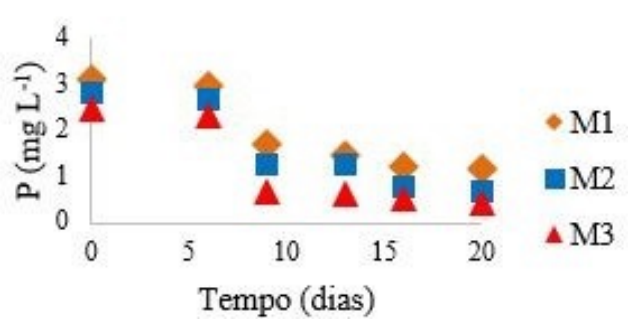

Figura 4 - Curvas de remoção dos nutrientes.

Tabela 5 - Resultados do pH da $3^{a}$ batelada.

\begin{tabular}{|c|c|c|c|}
\hline Dia & pH M1 & pH M2 & pH M3 \\
\hline 0 & 8,34 & 8,25 & 8,03 \\
\hline 6 & 9,13 & 8,80 & 8,19 \\
\hline 9 & 9,00 & 8,96 & 8,63 \\
\hline 13 & 9,10 & 8,89 & 7,82 \\
\hline 20 & 9,02 & 8,89 & \\
\hline
\end{tabular}

Observando a Tabela 5, nota-se uma elevação do $\mathrm{pH}$ em todas as misturas. Tal fato pode ser explicado devido ao consumo do carbono inorgânico pelas microalgas no processo de fotossíntese, ocasionando também a assimilação dos nutrientes. No entanto, esse aumento é tardio no tratamento com maior proporção de esgoto doméstico (M3), onde a presença de matéria or- gânica biodegradável no esgoto pode ter propiciado a geração de $\mathrm{CO}_{2}$ via respiração no começo da operação, evitando a elevação rápida de $\mathrm{pH}$. Essa observação é importante, pois interfere diretamente no mecanismo de remoção de nitrogênio amoniacal e fósforo solúvel. Em valores de $\mathrm{pH}$ mais elevados, a volatilização do nitrogênio amoniacal e a precipitação do fósforo solúvel 
podem ocorrer, levando à perda de nitrogênio para a atmosfera e a deposição do fósforo no reator, não contribuindo para a recuperação via assimilação pela biomassa, como pode ser visto em M1 e M2 onde se obteve um grande aumento do $\mathrm{pH}$ em relação ao dia 0 para o dia 6 .

\section{CONCLUSÃO}

Conclui-se que o tratamento em conjunto de lixiviado de aterro com esgoto doméstico a partir da produção de microalgas pode representar uma alternativa para a depuração de efluentes e, sobretudo, para recuperação de nutrientes existentes nos mesmos. Também foi evidenciado que a M3 que possuía a maior proporção de esgoto doméstico teve uma remoção de nutrientes de forma mais acelerada do que as demais, provavelmente com maior assimilação de nutrientes, favorecendo a recuperação dos mesmos.

\section{AGRADECIMENTOS}

Agradecemos ao Professor Dr. Eduardo de Aguiar do Couto pelas orientações e ensinamentos passados por todo o período da iniciação científica. E à nossa colega de pesquisa e amiga Daiana Gonçalves da Fonseca Silva.

\section{CONTRIBUIÇÃO DOS AUTORES}

Todos os autores contribuíram de forma igualitária.

\section{REFERÊNCIAS}

ACEVEDO, S.; PINO, N. J.; PEÑUELA, G. A. Biomass production of Scenedesmus sp and removal of nitrogen and phosphorus in domestic wastewater. Colombia: Ingeniería y Competitividad, v. 19, n. 1, p. 185-193, 2017.

ACIÉN, F. G.; GÓMEZ-SERRANO, C.; MORALES-AMARAL, M. M.; FERNÁNDEZ-SEVILHA, J. M.; MOLINA-GRIMA, E. Wastewater treatment using microalgae: how realistic a contribution might it be to significant urban wastewater treatment? Germany: Applied
Microbiology and Biotechnology, v. 100, n. 21, p. 9013-9022, 2016. https://doi.org/10.1007/s00253-016-7835-7

APHA. Standard Methods of the Examination of Water and Wastewater. Washington. American Water Work Association, Water Environmental Federation, 2012.

GANI, P.; SUNAR N. M.; MATIAS-PERALTA, H. M.; LATIFF, A. A.; KAMALUDIN, N. S.; PARJO, U. K.; EMPARAN, Q.; ER, C. M. Experimental study for phycoremediation of Botryococcus $s p$. on greywater. Switzerland: Applied Mechanics and Materials, v. 773-774, p. 1312-1317, 2015. https://doi.org/10.4028/www. scientific.net/AMM.773-774.1312

GARCÍA-GOZALBES, C. C.; ARBIB, Z.; PERALES-VARGASMACHUCA, J. A. Cinéticas de crecimiento y consumo de nutrientes de microalgas en aguas residuales urbanas con diferentes niveles de tratamento. México: Tecnología y Ciencias del Agua, v. 6, n. 1, p. 49-68, 2015.

NEDERLANDS NORM. NEN 6520. Water - Spectrophotometric determination of chlorophyll a contente. Netherlands. 1981.

NUSH, E. A. Comparisons of different methods for chlorophyll and phaepigment determination. Germany: Archiv für Hydrobiologie, v. 14, p. 4-36, 1980.

ÓRPEZ R.; MARTÍNEZ, M. E.; HODAIFA, G.; YOUSFI, F. EL; JBARI, N.; SÁNCHEZ, S. Growth of the microalga Botryococcus braunii in secondarily treated sewage. Netherlands: Desalination, v. 246 , n. $1-3$, p. $625-630,2009$. https://doi.org/10.1016/j. desal.2008.07.016

PASKULIAKOVA, A., TONRY, S., TOUZET, N. Phycoremediation of landfill leachate with chlorophytes: phosphate a limiting factor on ammonia nitrogen removal. UK: Water Research, v. 99, p. 180-187, 2016. https://doi.org/10.1016/j.watres.2016.04.029

RAS, M.; STEYER, J.; BERNARD, O. Temperature effect on microalgae: a crucial fator for outdoor production. Netherlands: Reviews in Environmental Science and BioTechnology, v. 12, p. 153-164, 2013. https://doi.org/10.1007/s11157-013-9310-6

RAWAT, I.; KUMAR R. R.; MUTANDA T.; BUX, F. Dual role of microalgae: phycoremediation of domestic wastewater and biomass production for sustainable biofuels production. UK: Applied Energy, v. 88, n. 10, p. 3411-3424, 2011. https://doi. org/10.1016/j.apenergy.2010.11.025

SAHU, O. Reduction of organic and inorganic pollutant from waste water by algae. Switzerland: International Letters of Natural, v. 13, p. 1-8, 2014. https://doi.org/10.18052/www. scipress.com/ILNS.13.1

ZHAO, X.; ZHOU, Y.; HUANG, S.; QIU, D.; SCHIDEMAN, L.; CHAI, X.; ZHAO, Y. Characterization of microalgae-bacteria consortium cultured in landfill leachate for carbon fixation and lipid production. UK: Bioresource technology, v. 156, p. 322-328, 2014. https://doi.org/10.1016/j.biortech.2013.12.112 